\title{
On the Biology of Bulgaria polymorpha, Wett.
}

\author{
BY \\ R. H. BIFFEN, \\ Botanist to the Agricultural Department, late Demonstrator of Botany \\ in the University of Cambridge.
}

\section{With Plate VII.}

PULGARIA POL YMORPHA in the neighbourhood of Cambridge is usually to be found on the bark of oaktrees which have been felled and allowed to lie in the woods for a year or two, but it has been recorded on living beech by Massee ${ }^{1}$, and again by Hennings on living oak ${ }^{2}$. Ludwig even considers it as a dangerous parasite on the oak ${ }^{3}$. As a rule the Fungus is a saprophyte, but as is so often the case, it is at times capable of becoming parasitic. De Bary calls such Fungi facultative parasites.

The Fungus has been described under the name of Peziza polymorpha by Oeder, Peziza inquinans by Persoon, Bulgaria inquinans by Phillips and Saccardo, and Bulgaria polymorpha by Wettstein ${ }^{4}$.

1 Massee, Textbook of Plant Diseases, I899, p. I62.

2 Hennings, Zeitschrift für Pflanzenkrankherten, iv, 266, I894.

3 Ludwig, Centr. für Bakt., 2. 52 I and 3. 633 .

4 Oeder, Flor. Dan., t. 464 (I768); Persoon, Syn. Fung., p. 631 (I801); Phillips, Brit. Disc., p. 314, I887 ; Saccardo, Syll., viii, n. 2625 ; Wettstein, Zool.Bot. Verh., I886, p. 595. For figures see Rehm, Krypt.-Flora, Discomycetes,

[A nnals of Botany, Vo1. XV. No. LVII. March, I90I.] 
I quote the description given by Massee $^{1}$ : 'Ascophores gregarious or caespitose, erumpent, at first more or less clavate, closed, rusty-brown, and scurfy, the disc gradually expanding and becoming plane or slightly convex, black and shining, externally umber-brown, wrinkled and scurfy, turbinate and narrowed into a short, stout, stem-like base, which is mostly buried in the substance of the host, $\mathrm{I}-4 \mathrm{~cm}$. across, and the same in height, gelatinous, flesh brown; asci cylindric-clavate, narrowed below into a long slender base, usually only containing four perfectly developed spores; spores I-seriate, continuous, elliptical slightly curved, I-2 guttulate, brown at maturity, $10-14 \times 5^{-6 \mu}$; paraphyses slender, slightly thickened, brownish, and more or less curved at the tips.'

In its gelatinous texture Bulgaria resembles the Tremellineae to such an extent, that a very similar species, $B$. sarcoides, was for some time considered to be a Tremella, and when the ascomycetous nature of the Fungus was proved it was considered by some to be a form connecting together the Discomycetes and Tremellineae.

The morphology of $B$. polymorpha was worked out in some detail by Tulasne ${ }^{2}$, and served him as a good example of a pleomorphic species at a time when little was known of the various spore-forms of the Ascomycetes. By observing specimens at different periods of the year Tulasne was able to show that at one time they produced pycno-conidia and spermatia, and then ascospores, which on germination gave rise to a conidial stage; that is, one and the same Fungus was capable of giving rise to four essentially different sets of spores. Brefeld ${ }^{3}$ has further studied the germination of the ascospores and the conidia formed from them.

p. 472 ; Tulasne, Ann. d. sci. nat., $3^{\mathrm{e}}$ sér., tom. $\mathrm{xx}$, p. $\mathbf{1} 64$; Brefeld, Unters. aus d. Gesammtgeb. d. Mykol., I89I, Heft x, Ascomyceten, ii ; Hussey, Illustr. Brit. Myc., P1. XXXII.

1 Massee, Brit. Fung. Flora, vol. iv, p. I 40, I893.

2 Tulasne, Ann. d. sci. nat., $3^{\Theta}$ sér., tom. xx, p. I64, I853; Tulasne, Carpologia, tom. iii, p. I92, I863; Tulasne, Bot. Zeit., p. 54,1853 .

3 Brefeld, Heft x, Ascomyceten, ii, p. 301 . 
My chief object in examining the biology of this Fungus was to observe the effects of its action on wood, but as the cultures afforded a good opportunity, the course of development was also traced in some detail.

The ripe ascophores used for this investigation were gathered on December 5, I898, and a further supply was obtained in December, 1899 . They are also said to occur during the summer months, but so far I have not found them except in the winter.

An examination of longitudinal sections of the ascophore showed that it was traversed by dark brown veins, which anastomosed immediately below the hymenium (Pl. VII, Fig. I). Under the microscope the veins were found to be channels bordered by hyphae with thin dark brown walls, while the mass of the ascophore consisted of hyphae with strongly swollen walls. To such an extent was this swelling carried that the walls formed a solid gelatinous mass.

The hymenium consisted of delicate whip-like paraphyses and asci characterized by containing two apparently different forms of ascospores-a comparatively rare occurrence in the Ascomycetes, for all eight spores are usually similar to one another. In this case four had thick dark-brown walls and a deep longitudinal infolding on one side, while the remaining four were colourless and thin-walled. The position of the smaller spores was variable, at times they were crushed into the apex of the ascus or scattered irregularly among the large brown spores. Occasionally, but very rarely, all the spores had thick brown walls. The apex of the ascus was coloured blue by an iodine solution.

On placing the ascospores in beer-wort gelatine they germinated within twenty-four hours (temp. $14^{\circ} \mathrm{C}$.), and rapidly gave rise to a dense mycelium. Both the coloured and colourless spores behaved in this way, and beyond the fact that the colourless spores germinated first I could find no difference between them. In about four days the walls of the mycelium began to swell, the swelling starting from the spore and gradually working its way along to the younger 
parts. At the same time a bright orange red pigment, the 'bulgarine' of Zopf, was formed within the hyphae. In the case of strongly-growing spores the swelling continued until the diameter of the hypha was increased three or four-fold. Except that a number of fusions occurred in hyphae extending beyond the hanging-drops, possibly as an aid for the transference of plastic substances, nothing further was to be noted in these cultures. This result does not agree with those of Brefeld and Tulasne, who have stated that the spores on germination put out either a rudimentary or a well-developed mycelium from which numbers of rodshaped conidia were abstricted ${ }^{1}$. Further experiments with various media showed, however, that either result could be produced at will. Thus on sowing the spores in distilled water the colourless ones germinated in about twenty-four hours and gave rise to a mycelium about the length of the original spore, from which numbers of conidia were abstricted, while the coloured spores behaved in a similar fashion after two or three days. In a watery extract of oak-wood, or in a gelatine made up with a watery extract of cow-dung, both colourless and coloured spores gave rise to a long, branching mycelium bearing clusters of conidia. It would appear therefore that the formation of the conidia is determined by the supply of available nutriment; where there is little, conidia are produced at once, while where there is plenty, mycelium only is formed.

The conidia themselves swelled considerably on germination and gave rise directly to a mycelium, which on transference to a moist, sterile block of oak-wood developed rapidly and infected it $^{2}$.

The germinating ascospores also are capable of infecting oak-wood directly, for on removing them from beer-wort gelatine to sterilized blocks they soon gave rise to a thick mycelium. As I never succeeded in finding conidia on the

1 Vide Brefeld, Heft x, Ascomyceten, ii, Plate XI, for figures.

2 For details of method, vide Marshall Ward, Phil. Trans., vols clxxxix, p. 123, 1897. 
mycelium on the blocks, I assume that the mycelium from the ascospore is capable of direct infection.

To study the action of the Fungus on wood, sterile blocks of oak and pine-wood were infected from plate-cultures of the ascospores, beer-wort gelatine being used for germinating them in. A week after infecting the blocks it was evident that the Fungus was growing satisfactorily, for the greater part of their surfaces was covered with a thin, tawny yellow felt of mycelium, which had further commenced to spread over the damp cotton-wool plugs on which they rested. The cultures on pine-wood went no further than this, but on the oak-wood the mycelium increased in quantity, turned to a darker brownish-yellow colour, and in three weeks' time small white humps of tissue appeared on them which gradually increased in size and at the same time exuded drops of water (Fig. 2). This secretion of water usually appears to occur when a Fungus is growing rapidly or is making some special effort, as for instance when spores are being produced. As a familiar case I may mention Polyporus hispidus, Fr., which while forming its basidiospores exudes quarts of water. The phenomenon is more readily observed in tubecultures, where evaporation is not so rapid as in the open. It is probably due to the necessity for large supplies of foodstuff, which have to be taken up in solution and the excess of water disposed of.

The development of these white humps proceeded slowly, and it was not until three months had passed that they appeared as the more or less scurfy, gelatinous knobs characteristic of the young ascophores. Externally their appearance was somewhat variable, some were light grey-brown in colour, others deep chestnut or even black. Those growing from the cotton-wool plugs were usually darkest in colour and had a sodden gelatinous appearance. Then the polished black hymenium opened out and in a few days shed its ascospores as a sooty-brown deposit on the sides of the tubes.

Cultures were fixed either by boiling, or with $20 \%$ alcohol, 
and then taken through the usual series of alcohols before examination for the effects of the Fungus on the wood.

The only noticeable effect on scrubbing off the external mycelium was that the wood was coloured an ochrey-yellow tint. Longitudinal and transverse sections of a block infected a month before fixing showed that all the tissues were thoroughly permeated by hyphae. The large vessels especially were crowded with mycelium, all of which showed the same swelling of the walls. In some cases the entire lumen of a tracheid was blocked by the much-swollen hypha-wall.

At the same time a slight swelling of the thickening layers of the woody elements was visible. On treating transverse sections with Schulze's solution, a few of the most swollen thickening layers gave a deep purple colour-suggesting that the action of the Fungus was one of delignification. In some cases the thickening layers had become detached and invaginated into the tracheids, owing to excessive swelling, in a similar manner to that described by Marshall Ward ${ }^{1}$ in the case of Stereum hirsutum (Fr.).

Where the swelling of the thickening layers was slight, Schulze's solution no longer gave either a golden yellow or purple colour, but the layers had a peculiar sheen, very like that of phloem-tissues, which soon became very characteristic of the early stages of delignification. This was followed by the gradual appearance of a faint violet and then purple colour. The kinking off into the lumen of the tracheid of the secondary from the primary thickening layer, or of the two together from the middle lamella, was never found to occur before their complete delignification. Meanwhile, as far as Schulze's solution showed, there was little change going on in the middle lamella; for it still stained a deep golden yellow colour, but in preparations from cultures two months old the elements became dissociated from one another, proving that it gradually went into solution.

Longitudinal sections also showed characteristic symptoms. The bordered pits of oak-wood seen in surface view, at some 
focal lengths appear to be surmounted by a cross with arms at right angles to one another. As the walls became swollen, one arm disappeared, while the other became an elliptical slit which gradually broadened until it was roughly circular in outline. Hartig ${ }^{1}$ figures a somewhat similar series of events in the case of oak-wood attacked by Thelephora perdix (Hartig), Stereum frustulosum (Fr.).

Schulze's solution, however, swells the walls of the elements to a considerable extent and so obscures many details. To obviate this I have used a saturated aniline-water solution of gentian violet and a saturated 50 per cent. alcohol solution of Congo-red. The sections were stained from sixteen to twenty-four hours in gentian violet and then transferred directly to the Congo-red solution, where they were usually left for an hour and then dehydrated and mounted in Canada balsam.

Tangential longitudinal sections of cultures a fortnight old were then for the most part stained an intense blue, except at pits where hyphae had passed through the walls. These pits were then marked by a sharply-defined, bright pink zone surrounding them, indicating that that portion of the wall had been delignified, and a cellulose basis staining with Congo-red remained.

In the case of cultures a month old this action was very marked, and one could easily find, especially in the vessels, walls in which every pit was marked in this way. Moreover no hyphae passed through the majority of these pits, so that one has to assume the secretion of a delignifying enzyme in quantity by the Fungus into the wood-elements. The rings round the pits gradually increased in size and in time met one another, so that the surface of the wall was marked by a clear blue network with angular patches at the corners of the mesh-work, on a pink ground (Fig. 3). Ultimately these angular patches disappeared also and the whole surface was stained pink owing to the entire delignification of the wall. The corresponding appearances in transverse section were

\footnotetext{
${ }^{1}$ Hartig, Zersetzungserscheinungen des Holzes, p. I03, and Taf. XIII, I878.
} 
readily traced in preparations from cultures six or eight weeks old. In these all stages of delignification were visible as a rule.

In the portions least attacked the thickening layers of the various elements were still stained an intense blue, except in the immediate region of pits, where the pink staining again indicated delignification, while in the portions most attacked they were pink throughout. The effect of the action of the Fungus on the middle lamella was also beautifully shown. At first the lamella stood out sharply as an intensely blue line, which gradually became thinner and thinner until it entirely disappeared, except at the corners where several cells met. Where the sections had passed through a pit the lamella was wanting on either side for some distance, and if the action had only just started, a lens-shaped patch of delignified tissue was clearly marked off round it (Fig. 4). In still more diseased portions the gradual disappearance of the angular portions of the middle lamella was traceable. They first became hollow owing to the solution of the so-called 'intercellular protoplasm' of Russow ${ }^{1}$ and then dissolved entirely (Fig. 5). In this stage the various elements were separated from one another and the wood readily crumbled away on sectioning. As far as my cultures go, this entire breaking up of the wood was of very local occurrence. It was never so complete as in the case of Stereum frustulosum, for example.

All the woody elements were attacked in precisely the same way, and at about the same period, with the exception of the tracheids of the medullary rays. These resisted the attack for some time and stood out as dark blue bands, in transverse sections, when almost the whole of the lignin had disappeared from the other elements. Ultimately they too were attacked, however, the action starting most frequently at the point where they abutted on a vessel.

The early stages of this localized delignification of the walls resemble the early stages in the destruction of the thick cellulose walls of the endosperm of germinating seeds of

${ }^{1}$ Gardiner, Proc. Camb. Phil. Soc., vol. v, pt. ii. 
Tamus communis. Gardiner ${ }^{1}$ has shown in these that the cytohydrolytic enzymes travel along the protoplasmic threads traversing the walls and dissolve them in their immediate neighbourhood. The action is most intense near the middle lamella, so that each thread seems to lie in a cone-shaped portion of the partially dissolved wall, the base of the cone resting on the middle lamella. Sections in the plane of the threads would therefore show a more or less lens-shaped patch of partially dissolved cellulose.

Although, as far as I know, no one has yet proved that threads exist in woody walls similar to those we are dealing with, yet it seems probable that they existed while the thickening layers were being deposited, so that there is a possibility that the pits and the walls are traversed by the minute passages they once occupied. If this is in reality the case, we may apply Gardiner's explanation of the destruction of the cellulose endosperm-walls to the destruction of the lignified walls, by assuming that a delignifying enzyme travels along the slender passages formerly occupied by the threads and decomposes the lignin in their neighbourhood. Whether the increased intensity of decomposition near the middle lamella is due to slight differences in the structure of the succeeding strata of the cell-walls or not has still to be proved. At all events, the first appearance of these delignified lensshaped patches and the gradual and regular spread of the delignification from the pits accord so well with the assumption made as almost to amount to a proof of the existence of protoplasmic threads, or of the passages once occupied by them in woody walls.

So far I have assumed the existence of a delignifying enzyme to explain these results. Such an enzyme has recently been isolated by $\mathrm{Czapek}^{2}$ from Merulius lacrymans and has been named Hadromase. Before seeing Czapek's paper I had considered that there was evidence for lignin being a glucoside capable of being split into pectic acid and

${ }_{1}^{1}$ Gardiner, Proc. Roy. Soc., I897-98, vol. 1xii, p. 100.

${ }^{2}$ Czapek, Ber, d. deutsch. bot. Ges., I899, xvii, p. I66. 
glucose, a view which is partially supported by the frequency of the occurrence of glucoside-splitting enzymes in wooddestroying Fungi ${ }^{1}$. To test this, a number of cultures on oak-wood saturated with five per cent. solutions of glucose, laevulose, maltose, cane-sugar, and xylose were made, on the assumption that where the glucose was already available the Fungus would no longer need to decompose the wood to obtain it, and also to see, if this was indeed the case, whether glucose could be replaced by any other sugar.

These cultures were examined at fortnightly intervals, and at first looked promising, for in every case except that of the glucose-saturated wood the mode of attack was normal. However, after the action had continued for six weeks the glucose-saturated wood showed the characteristic symptoms of attack, although, as subsequent analysis proved, glucose was still present.

At the same time it is worth noticing that the cotton-wool plugs at the base of the tubes usually produced a fine crop of ascophores, so that it might seem that the delignifying enzyme was not absolutely necessary for the welfare of the Fungus, since the plugs and watery extract of wood could contain no lignin. However, on attempting to grow the Fungus on cotton-wool soaked in a watery extract of oak-wood its development was so slight that it became certain that the necessary nutriment had been conveyed in the former case through the mycelium connecting the blocks to the cotton wool. At the present time our knowledge of the constitution of lignin and of the structure of the lignified cell-wall is exceedingly slight ${ }^{2}$. According to $\mathrm{Czapek}^{3}$ the lignified walls are composed of a hadromal-cellulose ester, which under the influence of the enzyme hadromase is split up, leaving a cellulose basis. Thus after treating wood with an aqueous extract of Merulius lacrymans, it shows the cellulose reaction when treated with Schulze's solution, while the

1 Bourquelot, Bull. de la Soc. Myc. de France, tom. viii, p. 13, I892.

2 Vide Green, Sci. Prog., vol. vi, p. 344, for a summary and literature, I897.

${ }^{3}$ Czapek, ibid. 
extract on concentration gives the usual lignin reactions with phloroglucin and hydrochloric acid.

The results already seen in the decomposition of the thickening layers agree with this inasmuch as a cellulose basis remains after the disappearance of the lignin, but the middle lamella is also delignified and moreover dissolved. It is impossible therefore to extend Czapek's results to include the middle lamella, which, as we know from the researches of Mangin and $\mathrm{Kabsch}^{1}$, is composed primarily of pectates, and yet is as lignified as, or more so, than the cellwalls. They show us merely that some Fungi have the power of dissolving out lignin as such. We have still to determine how Fungi utilize this presumably valuable foodstuff. That they do so seems certain, for on testing diseased wood with phloroglucin and hydrochloric acid I have never been able to find a trace of the red staining which should accompany unaltered lignin in the mycelium.

The results of the action of Bulgaria polymorpha upon oak-wood are, then, to dissolve and probably decompose the lignin, and to dissolve the pectates of the middle lamella. I have never seen any evidence, either in pure cultures or in naturally diseased wood, pointing to further action, as is the case when some Fungi first delignify the wood and then decompose the cellulose which remains. Moreover, the action is too slight in all the cases I have examined to warrant the supposition that the Fungus is capable of causing a really serious tree-disease such as Ludwig assumed.

The development of the ascophore has been traced from the pure cultures grown on oak-wood or on the cotton-wool plugs on which the blocks rested. The results agree with those of Tulasne ${ }^{2}$, except that I have been unable to find any spermatia or spermogonia. When, however, one attempts to completely cultivate Fungi in pure cultures one realizes how difficult it is to successfully imitate the diverse conditions

\footnotetext{
1 See previous page, note 2.

2 Tulasne, ibid. The account given here merely supplements that in the Ann. d. sci. nat.
} 
to which the naturally growing Fungi are exposed, and consequently to obtain all the possible spore-forms. I am therefore unwilling to doubt the accuracy of Tulasne's observations, even though my cultures have reached the ascusbearing stage.

In each case the ascophores were fixed in Keiser's solution and preserved in alcohol. The earliest stage examined is that shown as a white patch in the second figure. It consisted of a loose plexus of hyphae with such strongly swollen walls that no spaces were left between them, traversed here and there by hyphae with thin, dark walls. At the base of this a number of spherical portions were sharply delimited by walls built up of carbonized hyphae. At first they appeared as hollow shells, which in the course of a month became lined with a gelatinous mycelium, from which conidia (the stylospores of Tulasne) were abstricted. After this the conceptacles became full of a gelatinous mycelium, and by their subsequent growth formed the greater part of the ascophore (Fig. 6). Only the extreme upper portion, and fragments of the outer margin, which in part contributed to the formation of the scurfy scales, was derived from the original plexus. These scales were, for the most part, composed of hyphae with numerous septa and carbonized walls. As this rapid growth proceeded, the hyphae of the gelatinous portions became locally swollen into balloon-like outgrowths, which occasionally became carbonized, and then had somewhat the appearance of chlamydospores. This swelling usually began at knee-like bends in the hyphae (Fig. 7). I have only observed this in pure cultures, and have found no trace of it in naturally-growing specimens. The next observable stage was that a dense mass of paraphyses was developing between the original plexus and the still-distinguishable, carbonized walls of the conceptacles. At first they were straight, and then, as growth continued, sigmoidally curved owing to the resistance met with to their upward growth. Their obvious function was to bring about the opening and expansion of the disc. 
Owing to the contraction of the gelatinous hyphae when hardened in alcohol and their subsequent expansion when removed to water it was impossible to obtain a series of microtome-preparations, so that the search for antheridial and oogonial branches had to be abandoned. The early stages in the development of the ascus itself were easily observed, and as they were found to accord with those described by Harper ${ }^{1}$, Dittrich ${ }^{2}$, and Gjurasin ${ }^{3}$, need no further description.

In the young ascus the apex was appreciably thickened, and when treated with iodine solution a cylindrical plug, hollowed out towards the interior, was differentiated by staining a deep blue. As it increased in size the plug became stretched, and could only be distinguished with difficulty.

When the eight spores were first formed it was impossible to say which four would become thick-walled. Each had a single central nucleus which divided into two, and the daughter-nuclei travelled to the poles, while a large vacuole formed between them. Staining at this stage however, with Weigert's haematoxylon or with safranin-gentian violet, showed that some change was occurring, for four of the spores stained deeply, while four remained practically colourless, except at the poles. This was to be explained by the formation of a carbonized wall, almost impermeable to stains, round the developing spore. The brown-walled spores then increased slightly in size, and the deep longitudinal depression, giving the spore its characteristic appearance, developed. The colourless spores did not increase in size after the division of the original nucleus.

Lately Wisselingh has shown that the walls of fungal hyphae in the majority of cases consist of chitin, so that it became of interest to determine whether this was the case for the gelatinous walls met with in Bulgaria. On

1 Harper, Ann. of Bot., xiii, p. 467, I899.

2 Dittrich, Cohn's Beitr., viii, p. I 7, I899.

${ }^{3}$ Gjurasin, Ber. d. deutsch. bot. Ges., xi, p. I I 3, I 893 . 
adding an iodine solution, especially to sections of young ascophores, the gelatinous portion gave a pale blue or violet colour, while Schulze's solution coloured it a faint violet lavender. The bluish colour was often emphasized by the bright golden-staining contents of some of the hyphae. On heating the sections in sealed tubes with concentrated caustic potash, and then treating with sulphuric acid and iodine, every portion gave the characteristic rose-red colour of the chitin test ${ }^{1}$, so that the carbonized and gelatinous walls and the plug at the apex of the ascus have all a chitin basis.

The early stages in the development of the ascophore remind one to a certain extent of the life-history of some of the Pyrenomycetes, such for example as the Valsaceae or the Diatrypaceae among the Sphaeriaceae ${ }^{2}$. In these cases pycnoconidia (stylospores) are formed in conceptacles with walls of carbonized hyphae embedded in a stroma, and later these same conceptacles give rise to asci, and are then known as perithecia.

In Bulgaria polymorpha we also find a stroma in which pycnoconidia are developed, so that if the homology be granted, its ascophore consists of a number of perithecia welded together by subsequent growth (Figs. I and 8), while the stroma is reduced to the loose hyphae traversing the 'veins' and the apical portion of the ascophore which at first roofs over the hymenium. The hymenium itself in this case might be described as an overflow from the perithecia, the asci and paraphyses being carried out by the great development of gelatinous tissue in the perithecia, to form a regular layer above them instead of a number of isolated groups. Supposing, by way of another example, a series of similar changes to occur in a Xylaria, as a result we should have a Geoglossum.

Additional interest to this comparison of Bulgaria and a Sphaeria is afforded by the fact that in both cases the

1 Wisselingh, Prings. Jahrb., p. 6r9, I 898.

2 Tulasne, Carpologia, tom. ii, p. 97 and p. 2 I 2 , r 863. 
development is to a great extent carried on under the bark of the trees they grow on, while in the higher forms of the Discomycetes the apothecia are always formed superficially on the substratum. It is conceivable therefore that some such development has occurred as an aid to spore-distribution, the flattened exposed disc offering far greater facilities for dispersal than the almost closed and sunken perithecia.

On the other hand, in our ignorance of the phylogeny of the Ascomycetes, we may speculate as to whether the Sphaeriaceae have not developed in the opposite direction also, with the result that the perithecia with partially suppressed walls have become completely enclosed in the stroma. Such a structure would be very like those we meet with in the Tuberaceae. 


\section{34 Biffen.-On the Biology of Bulgaria polymorpha.}

\section{EXPLANATION OF FIGURES IN PLATE VII.}

Illustrating Mr. Biffen's paper on Bulgaria.

Fig. I. Longitudinal section through a ripe ascophore to show the 'veins.'

Fig. 2. A culture of the Fungus on oak-wood between three or four weeks old. The light patches are the earliest visible stages of the developing ascophores. $\times$ I.

Fig. 3. Pitted walls of oak-wood seen in surface view, showing various stages of delignification. Near the centre of the figure the pits have only recently been attacked, as shown by the narrow delignified zone surrounding them. These zones extend until they meet, as in the top left-hand corner, and ultimately the whole wall becomes delignified. $\times 375$.

Fig. 4. Transverse section of oak-wood to show the earliest stages in its decomposition. The delignified lens-shaped patches are to be associated with the position of 'pit-threads.' $\times 600$.

Fig. 5. A similar preparation to show the dissolution of the middle lamella. The central cell shows the middle lamella in its normal condition on the righthand side, while almost complete dissolution is shown in the right-hand bottom corner. The solution of the 'intercellular protoplasm' has just become visible. $\times 600$.

Fig. 6. A longitudinal section of an ascophore about $2 \mathrm{~mm}$. high, in which the conceptacles are developing rapidly to form the main mass of the ascophore. The dark portions indicate the position of carbonized hyphae.

Fig. 7. A portion of a similar section in detail. The hyphae have swollen out in a balloon-shaped fashion and acquired slightly thickened walls. $\times 375$.

Fig. 8. Transverse section of an adult ascophore for comparison with Fig. I. The net-like arrangement of the 'veins' is due to the number of carbonized conceptacle walls pressed together. $\times 25$. 

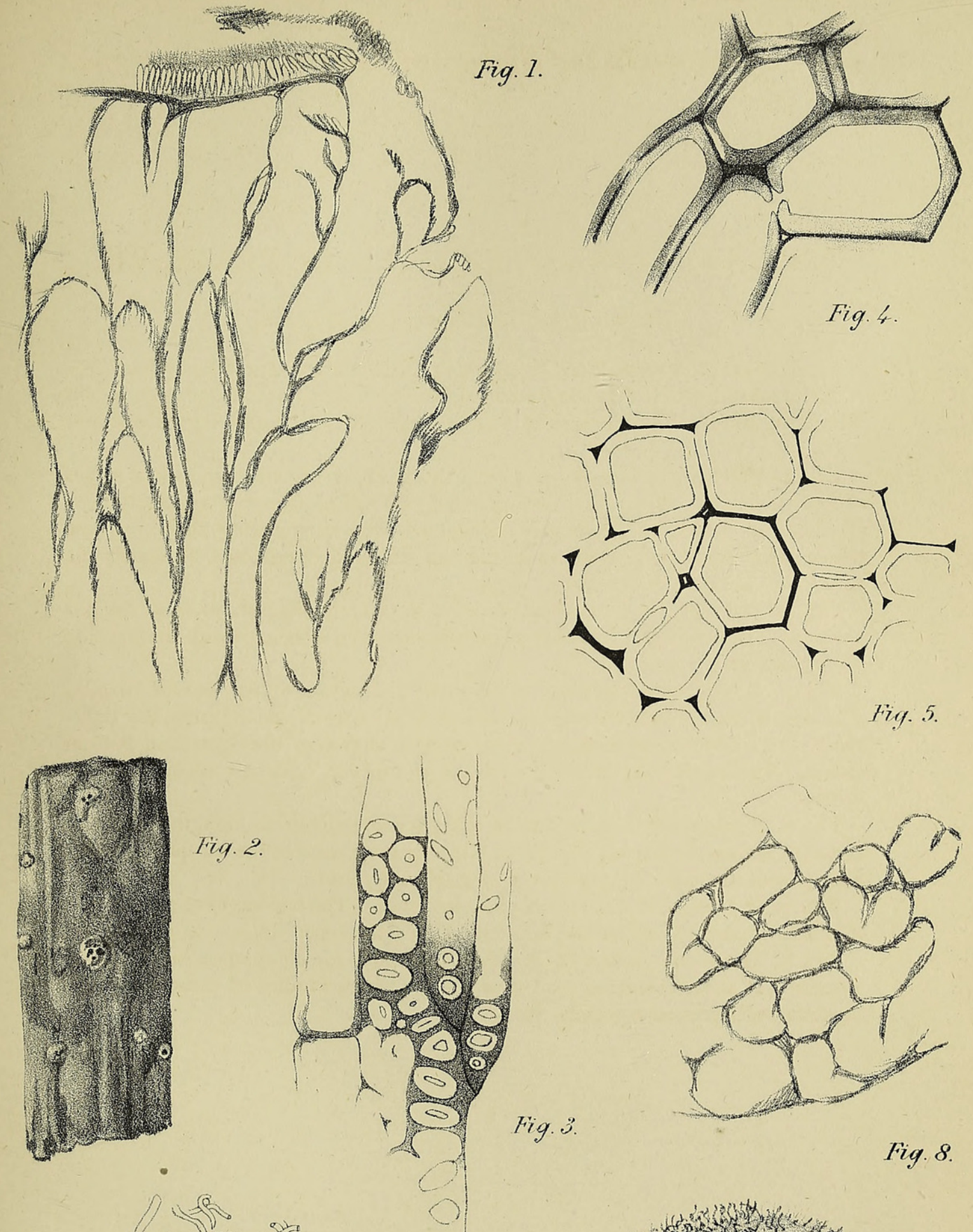

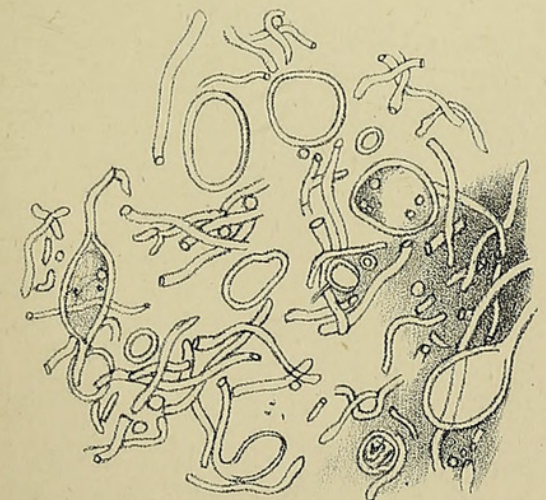

R.H.B. del.

Fig. 7

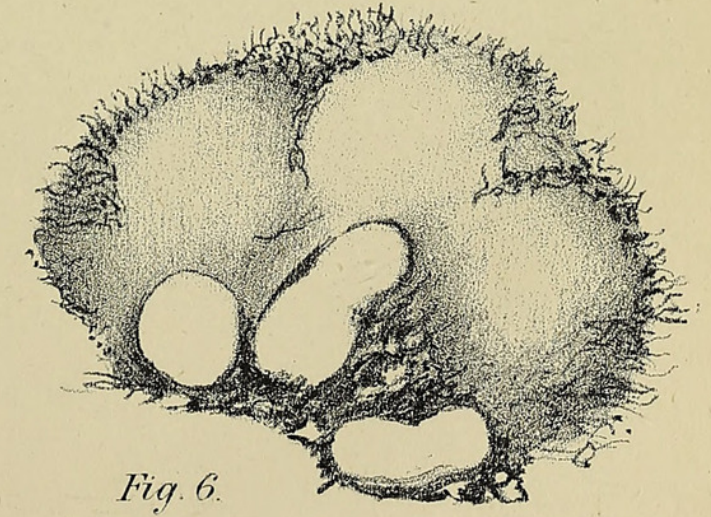

Univensity Press Oxford

BIFFEN.- BULGARIA. 


\section{$2 \mathrm{BHL}$ Biodiversity Heritage Library}

Biffen, Roland H. 1901. "On the biology of Bulgaria polymorpha, Wett." Annals of botany 15, 119-134. https://doi.org/10.1093/oxfordjournals.aob.a088807.

View This Item Online: https://www.biodiversitylibrary.org/item/236929

DOI: https://doi.org/10.1093/oxfordjournals.aob.a088807

Permalink: https://www.biodiversitylibrary.org/partpdf/318614

\section{Holding Institution}

Smithsonian Libraries

\section{Sponsored by}

Biodiversity Heritage Library

\section{Copyright \& Reuse}

Copyright Status: Not in copyright. The BHL knows of no copyright restrictions on this item.

This document was created from content at the Biodiversity Heritage Library, the world's largest open access digital library for biodiversity literature and archives. Visit BHL at https://www.biodiversitylibrary.org. 